\title{
Measurement of current distribution in a free-breathing PEMFC
}

\author{
Matti Noponen*, Tuomas Mennola, Mikko Mikkola, Tero Hottinen, Peter Lund \\ Laboratory of Advanced Energy Systems, Helsinki University of Technology, P.O. Box 2200, 02015 Hut, Finland
}

\begin{abstract}
A measurement system for the mapping of current distribution in a free-breathing polymer electrolyte membrane fuel cell (PEMFC) is introduced. In the measurement system, the ridges of the flow-field are made of gold-plated stainless steel and the rest of the measurement plate is made of a non-conducting material. The gas diffusion layer is not segmented and the error resulting from this is analyzed computationally. The effect of the cell temperature on the current distribution is studied with the measurement system. It appears that the measurement system is useful for PEMFC characterization and even large spatial variations of current density can be measured with it. According to the results, the optimum operating temperature for the studied cell is around $60{ }^{\circ} \mathrm{C}$ without external humidification. In addition, it is concluded that the molecular diffusion is dominating mass transport mechanism at low temperatures but the current density profile is more homogeneous at elevated temperatures. (C) 2002 Elsevier Science B.V. All rights reserved.
\end{abstract}

Keywords: Current distribution; Mass transport; Free-breathing cathode; PEMFC

\section{Introduction}

Polymer electrolyte membrane fuel cells (PEMFCs) are one of the most interesting alternatives for clean power production in automotive applications and for distributed power generation. The PEMFC might also be a viable alternative in many special applications where a highly reliable source of electricity is needed. These include telecommunication, marine and military applications.

Small and portable applications have received considerably less attention than large PEMFC systems. However, fuel cells may offer significant benefits in small applications because longer operating times can be achieved compared to battery technologies. To make fuel cells viable for small applications both the fuel cells themselves and system solutions need to be developed further.

One of the major challenges in the development of small PEMFC systems is to minimize the need of auxiliary components because they all lower the energy conversion density. Because of this, we examined the possibility of operating a fuel cell with free convection at the cathode side and without external humidification. Because the current production of a fuel cell is directly proportional to the oxygen concentration of the air stream, inadequate airflow results in heterogeneous current distribution in the fuel cell. These in turn decrease the active area of the fuel cell and thus reduce the performance. With our measurement system

\footnotetext{
* Corresponding author. Tel.: +358-9-451-3209; fax: +358-9-451-3195 E-mail address: matti.noponen@hut.fi (M. Noponen).
}

current distribution can be directly measured from a working PEMFC.

The current distribution inside a fuel cell is most often studied through simulations. Only few experimental studies have been reported [1-5]. These measurements give important insights into mass transport properties and also to other performance limiting factors of a fuel cell.

In the following chapters, the relation between the current distribution and mass transport in a free-breathing PEMFC is discussed. Furthermore, the principles and the implementation of the measurement system are described and the measurement results are presented. Finally, a computational study is presented in which the effect of the non-segmented gas diffusion layer on the current distribution is discussed.

\section{Mass transport phenomena and current distribution in free-breathing PEMFC}

In this paper we focus on a free-breathing cathode design. Its essential characteristic is straight vertical and parallel channels that extend from one edge of the flow-field plate to another. The ends of the channels are open to the ambient air. Oxygen is transported to the electrode directly from ambient air by free convection, which is driven by thermal convection and molecular diffusion. Thermal convection is caused by the temperature gradient between ambient air and the fuel cell whereas molecular diffusion is driven by concentration gradients. These arise when oxygen is consumed and water is produced in the fuel cell reactions. 
Because both the decreasing oxygen and increasing water concentration reduce the total molecular mass of air, molecular diffusion creates an upward velocity for the air in the channels. Thermal convection creates also upward velocity because of the buoyancy forces. Therefore, the direction of bulk airflow in vertical channels can be expected to be upwards. The strength of molecular diffusion depends on the total current and thermal convection on the temperature difference between the cell and ambient air. It is likely, however, that inside the cell air quickly reaches the temperature of the channel walls and therefore significant thermal gradients exist mostly near the ends of the channels.

In order to achieve stable and homogenous performance in the entire area of the electrode, the velocity of air should be such that oxygen concentration is as homogenous as possible and at the same time the water balance is maintained. The first requirement alone would obviously be satisfied by maximizing the airflow. From the point of view of water balance, the situation is more complicated. When current is drawn from the cell, activation and diffusion overpotentials as well as Ohmic resistances start to arise and all of them are connected to the water and temperature management of a fuel cell.

Activation overpotentials arise from the limited kinetics of the electrochemical reactions in the electrodes and are thus proportional to the oxygen concentration. In addition, because the electrodes usually contain Nafion ${ }^{\circledR}$, drying of the proton conductive phases of the electrodes may cause severe performance losses [6]. Ohmic losses are mostly due to the protonic resistance of the membrane. Also most common membranes are based on Nafion ${ }^{\circledR}$ in which the proton conductivity depends on the rate of hydration [7]. In small and mobile applications, internal humidification of the membrane is desirable. It can be achieved for example with thin membranes, in which the back diffusion of water is strong enough to keep the membrane proton conductive [8]. In a free-breathing fuel cell, mass transport overpotentials can be severe already at relative small current densities. This is due to inadequate velocity of the air stream and the difficulty of water removal. Both velocity and evaporation are increased at elevated temperatures, which on the other hand may result in decreased proton conduction.

Because the current production is directly proportional to the oxygen concentration, the overpotentials and Ohmic resistances become also either directly (mass transportation and activation) or indirectly through water management (activation and Ohmic resistance) proportional to oxygen concentration. This in turn creates a disturbed current distribution.

\section{Principles of current density mapping methods}

Different current density mapping methods have been reported in the literature. Cleghorn et al. [1] and Stumper et al. [2] have reported the use of a segmented flow-field plate and an electromagnetic approach has been studied by Wieser et al. [3,4]. Stumper et al. [2] used three different methods to measure current distribution. They found that the segmented flow-field plate approach is the most suitable for PEMFC.

The basic idea of the segmented flow-field plate approach is to divide a current collector into parallel, conductive segments, which are electrically insulated from each other. In one variation of the method, reported by Cleghorn et al. [1], this was achieved by using a printed circuit board as current collector. In other studies, the current collector structure has been reported to consist of electrically conductive collector pieces in a non-conductive supporting structure. In both cases currents from different cell areas can be measured independently.

In the electromagnetic approach, current gradients were measured with Hall-sensors. According to Wieser et al. [3], the advantage of this measurement method is its easy integration into the structure of a fuel cell stack. However, to our knowledge, current distribution measurements using Hall-sensors in a stack have not yet been reported. Also, it must be remembered that in a stack Hall-sensors would measure not only the current distribution of a single cell, but in addition the current distribution of the adjacent cell would affect the results.

In this study the segmented flow-field plate approach was used. This was chosen primarily because it was believed that a good spatial resolution could be achieved. In the segmented flow-field plate approach, measurements can also be done at one cell level within the stack structure. The weakness of this approach is the difficulty of achieving good contact between the current collector pins and the gas diffusion layer. On the other hand, it has been reported that similar kinds of problems can occur in non-segmented plates [3].

An important consideration relating to the segmented current collector approach is the question of whether the segmentation should be extended to the gas diffusion layers and even to the electrodes. Segmenting also these components would ensure that each pin is collecting current from a precisely known geometric area. On the other hand, segmenting them would significantly complicate the measurement system and it might change the diffusion properties of the gas diffusion layer. In our system the gas diffusion layer and electrodes were thus not segmented. The possible errors resulting from this are discussed in Section 6.

In most studies previously reported in the literature [1-4], current distribution was measured from the anode side. In the system reported here, however, the cathode side was segmented. This choice was made because segmentation makes it more difficult to achieve complete gas tightness. However, at the cathode side of a free-breathing single cell the structure does not have to be completely leakage proof, which makes the manufacturing of the flow-field plate easier. Leakage at the anode side would result in reduced performance due to mixed potentials caused by oxygen reaching the anode. 


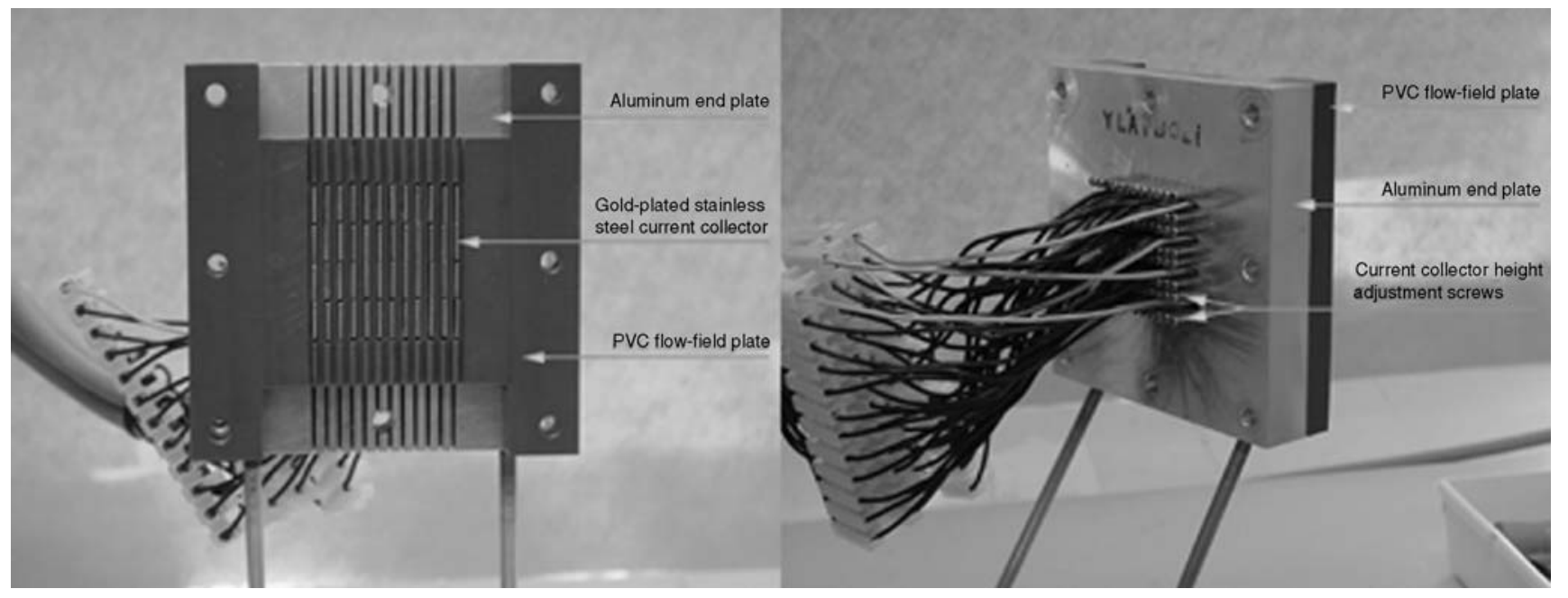

Fig. 1. The left-hand figure illustrates the flow-field plate and the current collectors, and the right-hand figure shows the end plate and the adjustment screws.

\section{Measurement system}

Figs. 1 and 2 show the structure of the cathode side flowfield plate. The matrix of the plate is made of PVC plastic. It forms the supporting structure of the plate and serves as insulator between the current collectors. The current collectors are made of gold-plated stainless steel. Stainless steel itself does not provide the necessary low contact resistance and long-term chemical stability. Noble metal plating, such as gold, decreases both problems. The end plate is made up of aluminum. Its purpose is to strengthen the structure because the PVC plate alone would bend when the retaining bolts are tightened. Each current collector has two screws for height adjustment so the contact pressure between the collectors and the gas diffusion layer can be individually adjusted for each collector piece.

As far as the authors know, no thorough channel structure optimization for free-breathing PEMFCs has been reported in the literature. For our measurement cell, the choice of the channel geometry was based on our previous experiments $[9,10]$. The active area of the fuel cell was chosen to be $5 \mathrm{~cm} \times 5 \mathrm{~cm}$ of which current collectors covered $11.2 \%$. The width and depth of the cathode channels were $3 \mathrm{~mm}$ and the width of the ridges was $1 \mathrm{~mm}$.

PVC plastic was chosen for non-conductive material because of its chemical and thermal stability at the operation condition range of a PEMFC. To the center area of the PVC plate, 12 slits were made. Current collectors were inserted into the slits, four collectors into each. The current collectors were $12 \mathrm{~mm}$ long and $1 \mathrm{~mm}$ thick with a current wire soldered to the end of each plate. The collectors were inserted through the PVC plate so that $0.7 \mathrm{~mm}$ gap was left between adjacent collectors in the direction of a slit. From the point of view of the gas flow this means that the channel geometry is not strictly straight 13 contiguous channels. In this structure, air can also leak slightly from one channel to another.

The end plate was constructed from aluminum. Four $55 \mathrm{~mm}$ long horizontal holes were drilled to the end plate in order to allow the current wires to come out through it. In addition, 12 vertical grooves were made to the same line as the slits in the PVC plate to allow current collectors to extend inside the end plate. The part of the current collectors going into the aluminum plate was insulated with a glass-fiber thread and an insulator was placed between each current collector and its adjustment screws.

Fig. 3 illustrates the measurement system. Each current collector pin was connected through a $0.1 \Omega$ high-resolution resistor to a load unit. The voltage drop over each resistance was monitored with a data logger, which further was controlled with a PC computer.

The $0.1 \Omega$ resistors were made of 10 parallel connected $1.0 \Omega$ carbon-film resistor with an accuracy of $\pm 0.5 \%$. Each current collector plate had a $0.1 \Omega$ resistor of its own so the

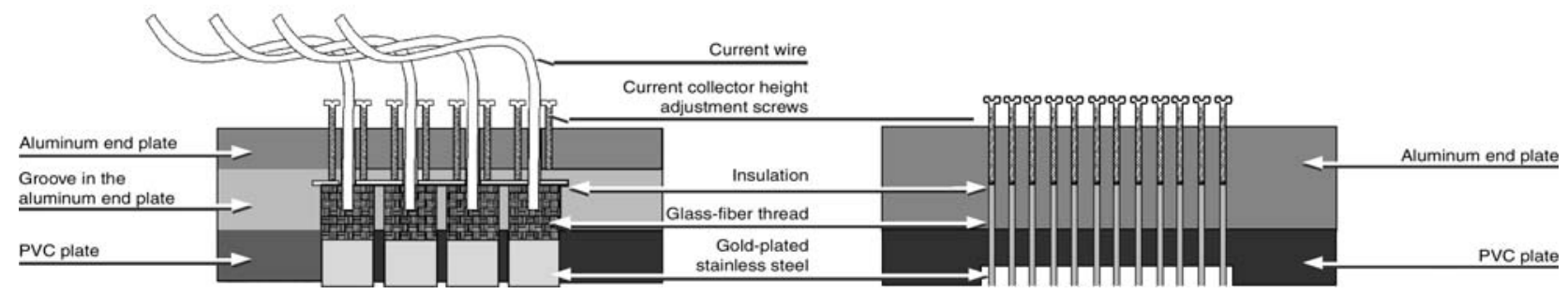

Fig. 2. Cross-sections from the segmented cathode flow-field plate. The left one is the vertical and the right one is the horizontal cut. 


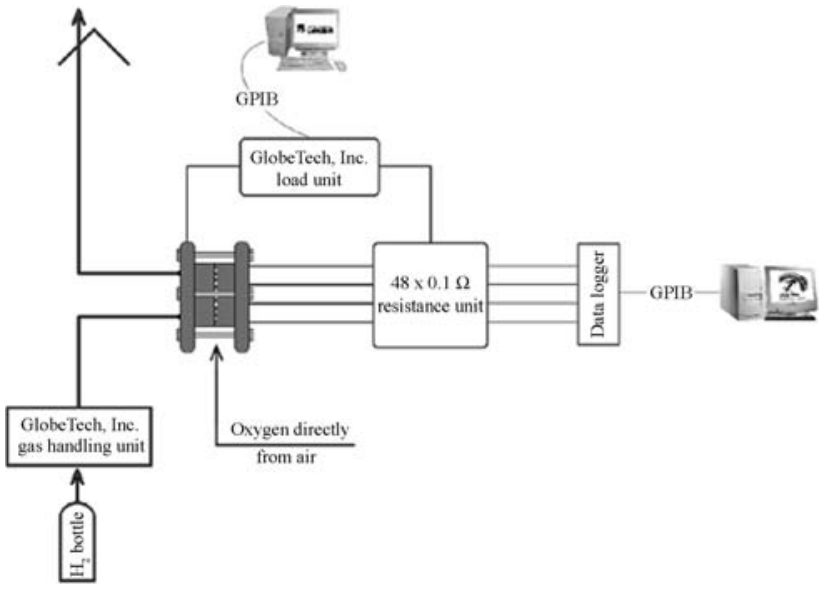

Fig. 3. The measurement system.

system contained a total of 48 resistors. The area specific current density $i_{i, j}$ could be calculated from the voltage readings $u_{i, j}$ measured over the $0.1 \Omega$ resistors by using the Ohm's law:

$i_{i, j}=\frac{1000 u_{i, j}}{a_{i, j} R}$

where $a_{i, j}$ is the area from which a current collector pin collects current $i_{i, j}, R$ is the measurement resistance, and the subscripts $i$ and $j$ define the placement of a measurement pin.

When the gas diffusion layer is not segmented, the areas $a_{i, j}$ may not be exactly equal. This may be caused, for example, by imperfect contacts between the pins and the gas diffusion layer or local dry areas of the membrane, which distort the voltage profile in the diffusion layer. The first approximation is that all the areas $a_{i, j}$ are equal and they can be calculated by dividing the total active area by the number of measurement pins. Eq. (1) thus leads to a simple form:

$i_{i, j}=19200 u_{i, j}$

A Hewlett Packard 7500 series B data logger was used to measure the voltage readings $u_{i, j}$. If only one channel was measured at a time, the measurement time was approximately $0.1 \mathrm{~s}$.

The load and the gas handling units were from GlobeTech, Inc. (now a part of ElectroChem, Inc.). The load unit measures the Ohmic resistance of a PEMFC by using the current interruption method. The resistance is calculated from the difference between the voltage before the current interruption and just after it. In order to verify the accuracy of the resistance measurement, the current interruptions were monitored using a digital oscilloscope as a continuous voltage-sampling device. Based on our results [11], the current interruption system appears to systematically overestimate the Ohmic resistance by approximately $20 \%$. Despite the error, qualitative conclusions can still be made from the data. The error results from the slow measurement of the voltage and from the capacitances of our cell. In addition according to Büchi et al. [12], either linear or exponential correction should be used so that the effect of the relaxation of electrochemical overpotentials would not distort the result.

The GlobeTech gas handling unit controls hydrogen mass flow and humidity levels. In these measurements, the minimum flow of hydrogen was set to $20 \mathrm{~cm}^{3} \mathrm{~min}^{-1}$ and for larger flows a relation $15 \mathrm{~cm}^{3} \mathrm{~min}^{-1} \mathrm{~A}^{-1} \times I$, where $I$ is total current of the fuel cell, was used. Hydrogen was fed into the cell without humidification or warming. The purity of the hydrogen was $99.999 \%$.

Because the examined fuel cell was of free-breathing type and ambient air was used as oxidant, the velocity and humidity of the air stream could not be actively controlled. However, attempts were made to carry out the measurements under constant temperature and humidity conditions. Ambient conditions were measured with a humidity and temperature probe.

As the anode side flow-field, a commercial graphite plate manufactured by GlobeTech was used. Channel geometry of this plate was serpentine with three parallel channels. The gas diffusion layers at both cell sides were SGL Carbon SIGRACET $^{\circledR}$ GDL $10-\mathrm{H}$ and the MEA was PRIMEA MEA $^{\circledR}$ from Gore. At the anode side gold coated copper plate served as the end plate and current collector. The segmented plate was used as the cathode flow-field. In addition, a sheet of paper was enfolded around the top section of the fuel cell in order to stabilize the cathode side airflow conditions.

\section{Measurements}

The purpose of the measurements was to demonstrate the ability of the measurement system to map current density distributions from a working PEMFC. In addition, the effect of the fuel cell temperature to the current distribution on a free-breathing cathode structure was investigated. Measurements were performed at four different cell temperatures and at two constant currents while ambient conditions were stable.

The measurement procedure was the same in all measurements. The cell was heated to the desired temperature, operated for $15 \mathrm{~min}$ at $2.5 \mathrm{~A}$, current distributions were measured for $15 \mathrm{~min}$, and finally a polarization curve was measured. Each constant current point in the polarization curves was measured at least for $10 \mathrm{~s}$ and the current range was scanned from the minimum to the maximum and then back to the minimum, always in this order. The data points were taken in galvanostatic mode. If the voltage did not remain stable at a constant current, the measurement time was extended. Ambient temperature, 45,60 , and $75{ }^{\circ} \mathrm{C}$ were chosen for the cell temperatures in the measurements. Ambient temperature varied between 27.2 and $28.5^{\circ} \mathrm{C}$ and the relative humidity of the air between 48.2 and $50.3 \%$.

Current density distributions at measurement temperatures are depicted in Figs. 4-9. The average current density 


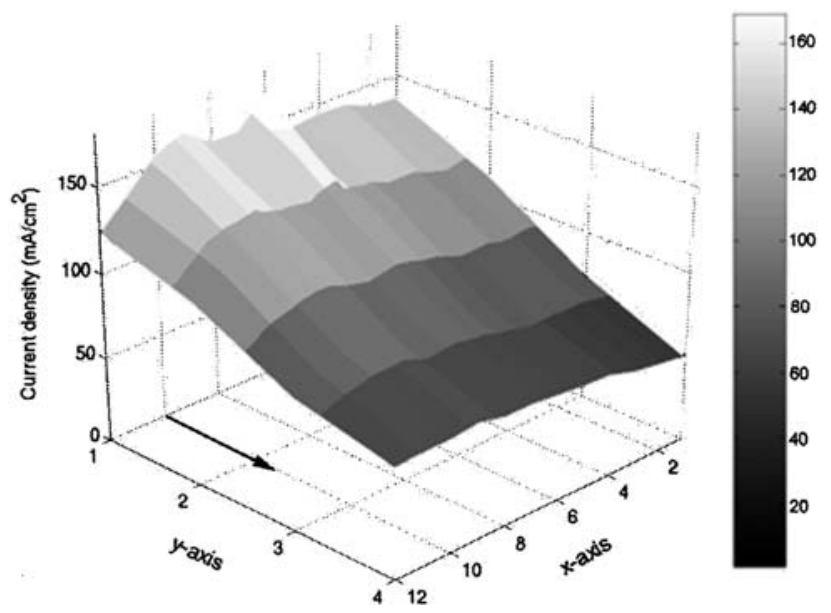

Fig. 4. Current density distribution at ambient cell temperature. Average current density is $100 \mathrm{~mA} \mathrm{~cm}^{-2}$.

in Figs. $4-7$ is $100 \mathrm{~mA} \mathrm{~cm}^{-2}$ and in Figs. 8 and 9 it is $200 \mathrm{~mA} \mathrm{~cm}^{-2}$. The airflow direction, which is from bottom to top, is marked in the figures with an arrow. The measured current density readings can be read from the crossing point of the $x$ - and $y$-axes and a linear interpolation was used between the readings from adjacent pins. In addition from Figs. 4-9, a percentual difference to a reference case was calculated. The reference is ambient cell temperature in the case of the average current density of $100 \mathrm{~mA} \mathrm{~cm}^{-2}$ (Tables 1-3) and $45{ }^{\circ} \mathrm{C}$ in the case of average current density of $200 \mathrm{~mA} \mathrm{~cm}^{-2}$ (Table 4).

From the current density distribution results, a few common features can be observed. The performance close to the hydrogen inlet (located at the area of the pin $(1,4)$, where 1 refers to horizontal and 4 to vertical pin number) was slightly reduced because dry hydrogen was used. This resulted in drying of the proton conductive phases of these areas. The effect can be seen most clearly from Figs. 5 and 6 (and from

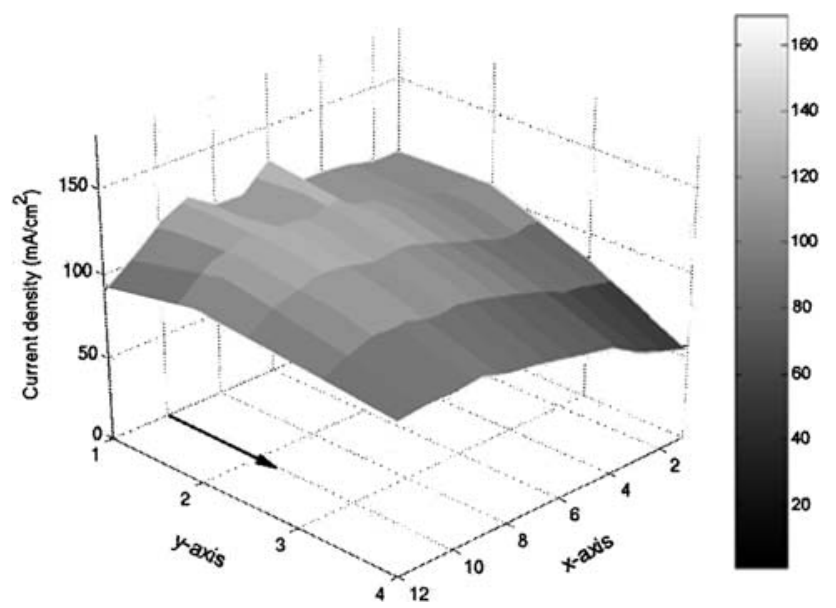

Fig. 5. Current density distribution at cell temperature of $45^{\circ} \mathrm{C}$. Average current density is $100 \mathrm{~mA} \mathrm{~cm}^{-2}$.

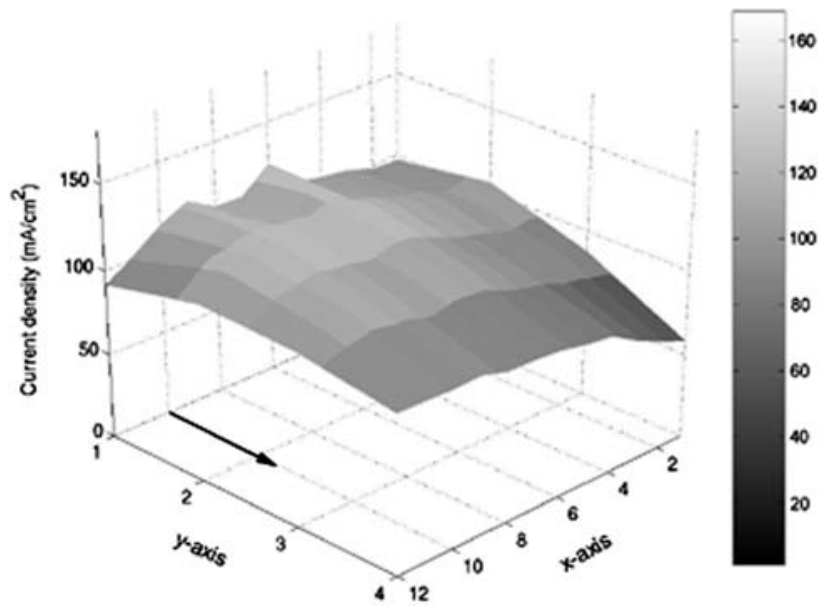

Fig. 6. Current density distribution at cell temperature of $60^{\circ} \mathrm{C}$. Average current density is $100 \mathrm{~mA} \mathrm{~cm}^{-2}$.

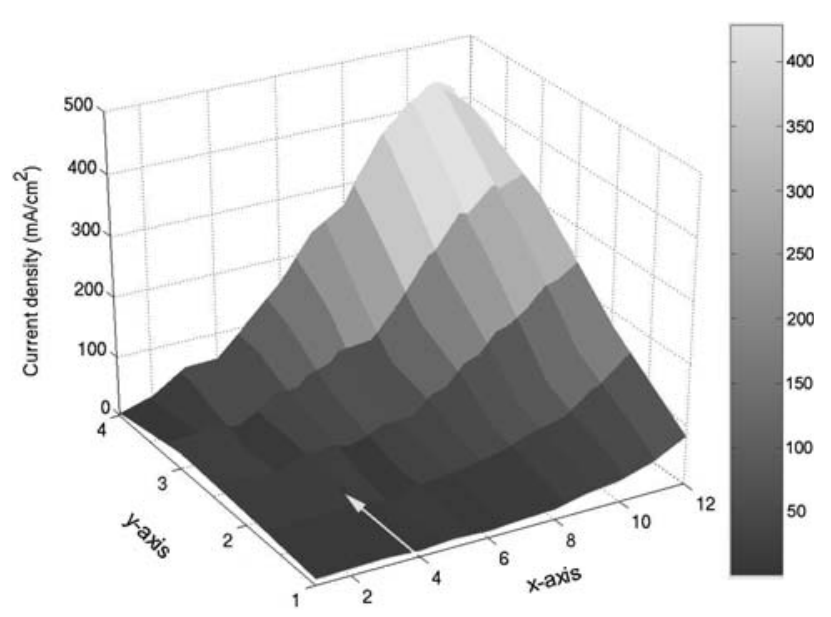

Fig. 7. Current density distribution at cell temperatures of $75^{\circ} \mathrm{C}$. Average current density is $100 \mathrm{~mA} \mathrm{~cm}^{-2}$.

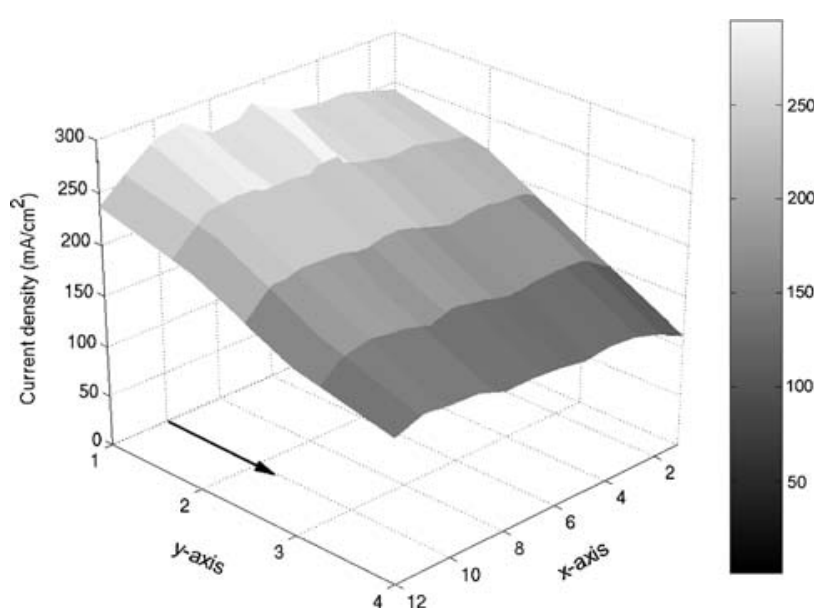

Fig. 8. Current density distribution at cell temperatures of $45^{\circ} \mathrm{C}$. Average current density is $200 \mathrm{~mA} \mathrm{~cm}^{-2}$. 


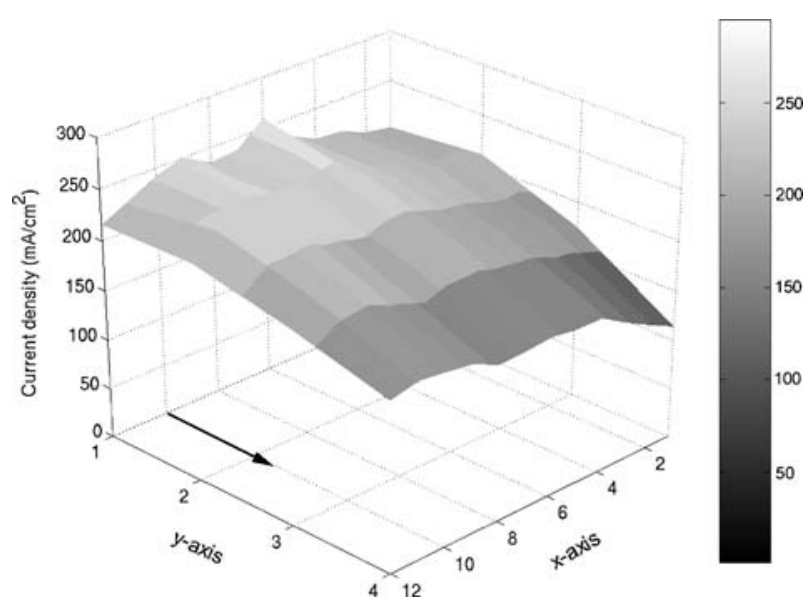

Fig. 9. Current density distribution at cell temperatures of $60{ }^{\circ} \mathrm{C}$. Average current density is $200 \mathrm{~mA} \mathrm{~cm}^{-2}$.
Tables 1 and 2). The right hand corner in these figures is clearly bent downwards and the percentual performance improvement is weaker.

Another common feature between the figures is that the pins $(6,1)$ and $(8,1)$ operated better than the surrounding ones. This is due to their better contacts on the gas diffusion layer. However, the difference between these pins and the adjacent ones was not greater than $10 \%$ and the difference was the same at all temperature levels as can be seen from the tables.

Fig. 4 illustrates the current distribution for the fuel cell at ambient cell temperature. Because there is no temperature gradient increasing the airflow, the molecular diffusion seems to be the dominating effect in oxygen transportation. However, molecular diffusion is not strong enough to transport oxygen evenly to all areas of the cell, which creates a heterogeneous current density distribution. Furthermore,

Table 1

The percentual difference between the current distribution at ambient cell temperature to the distribution at $45{ }^{\circ} \mathrm{C}$

\begin{tabular}{lccccccccccccc}
\hline Pin \# & $1(\%)$ & $2(\%)$ & $3(\%)$ & $4(\%)$ & $5(\%)$ & $6(\%)$ & $7(\%)$ & $8(\%)$ & $9(\%)$ & $10(\%)$ & $11(\%)$ & $12(\%)$ \\
\hline 4 & 11 & 14 & 21 & 27 & 31 & 33 & 35 & 39 & 39 & 40 & 40 & 40 \\
3 & 13 & 13 & 15 & 27 & 27 & 26 & 25 & 26 & 23 & 25 & 25 & 25 \\
2 & -3.9 & -6.7 & -6.8 & -3.5 & -2.9 & -1.6 & -1.5 & -0.0 & -2.0 & -3.5 & -3.5 & -3.5 \\
1 & -23 & -24 & -25 & -24 & -23 & -23 & -24 & -24 & -22 & -24 & -26 & -26 \\
\hline
\end{tabular}

${ }^{\text {a }}$ Average current density was $100 \mathrm{~mA} \mathrm{~cm}^{-2}$.

Table 2

The percentual difference between the current distribution at ambient cell temperature to the distribution at $60{ }^{\circ} \mathrm{C}$

\begin{tabular}{lccccccccccccc}
\hline Pin \# & $1(\%)$ & $2(\%)$ & $3(\%)$ & $4(\%)$ & $5(\%)$ & $6(\%)$ & $7(\%)$ & $8(\%)$ & $9(\%)$ & $10(\%)$ & $11(\%)$ & $12(\%)$ \\
\hline 4 & 15 & 21 & 29 & 34 & 36 & 37 & 36 & 37 & 36 & 40 & 40 & 44 \\
3 & 16 & 16 & 18 & 27 & 27 & 29 & 27 & 24 & 21 & 26 & 28 & 32 \\
2 & -5.2 & -7.0 & -5.8 & -2.6 & -2.3 & -0.3 & -0.7 & -0.8 & -3.1 & -3.1 & -1.9 & -1.4 \\
1 & -29 & -29 & -29 & -27 & -25 & -26 & -26 & -26 & -25 & -27 & -27 & -26 \\
\hline
\end{tabular}

a Average current density was $100 \mathrm{~mA} \mathrm{~cm}^{-2}$.

Table 3

The percentual difference between the current distribution at ambient cell temperature to the distribution at $75{ }^{\circ} \mathrm{C}^{\mathrm{a}}$

\begin{tabular}{|c|c|c|c|c|c|c|c|c|c|c|c|c|}
\hline Pin \# & $1(\%)$ & $2(\%)$ & $3(\%)$ & $4(\%)$ & $5(\%)$ & $6(\%)$ & $7(\%)$ & $8(\%)$ & $9(\%)$ & $10(\%)$ & $11(\%)$ & $12(\%)$ \\
\hline 4 & -94 & -64 & -1.4 & -7.4 & 75 & 151 & 255 & 308 & 419 & 515 & 539 & 485 \\
\hline 3 & -65 & -65 & -87 & -45 & -40 & -20 & -23 & 41 & 103 & 170 & 241 & 296 \\
\hline 1 & -92 & -92 & -91 & -94 & -90 & -94 & -91 & -90 & -82 & -77 & -63 & -36 \\
\hline
\end{tabular}

${ }^{\mathrm{a}}$ Average current density was $100 \mathrm{~mA} \mathrm{~cm}^{-2}$.

Table 4

The percentual difference between current distribution at $45{ }^{\circ} \mathrm{C}$ to the distribution at $60{ }^{\circ} \mathrm{C}^{\mathrm{a}}$

\begin{tabular}{|c|c|c|c|c|c|c|c|c|c|c|c|c|}
\hline Pin \# & $1(\%)$ & $2(\%)$ & $3(\%)$ & $4(\%)$ & $5(\%)$ & $6(\%)$ & $7(\%)$ & $8(\%)$ & $9(\%)$ & $10(\%)$ & $11(\%)$ & $12(\%)$ \\
\hline 4 & 2.6 & 2.1 & 6.2 & 14 & 19 & 18 & 14 & 13 & 15 & 17 & 16 & 18 \\
\hline 3 & 7.2 & 1.8 & 2.8 & 8.9 & 13 & 12 & 8.6 & 7.7 & 8.9 & 14 & 15 & 20 \\
\hline 1 & -16 & -18 & -16 & -14 & -11 & -12 & -12 & -12 & -13 & -14 & -12 & -8.9 \\
\hline
\end{tabular}

${ }^{\mathrm{a}}$ Average current density was $200 \mathrm{~mA} \mathrm{~cm}^{-2}$. 
because molecular diffusion creates an upward airflow, the bottom parts of the fuel cell operate best due to the highest oxygen concentration. The average voltage of the fuel cell was $0.65 \mathrm{~V}$ at this current.

Figs. 5 and 6 illustrate the current density distributions at 45 and $60{ }^{\circ} \mathrm{C}$ and Tables 1 and 2 the relative difference to the ambient case. At both temperatures the current distribution is relatively smooth, which means that the airflow is strong enough to form a fairly homogenous oxygen concentration along the gas channel. Elevating the cell temperature from 45 to $60{ }^{\circ} \mathrm{C}$ resulted in only a small performance improvement. The average voltage at $45^{\circ} \mathrm{C}$ was $0.73 \mathrm{~V}$ and at $60{ }^{\circ} \mathrm{C}$ it was $0.74 \mathrm{~V}$. It appears that no severe flooding or drying problems occurred at ambient cell temperature or at 45 and $60{ }^{\circ} \mathrm{C}$. Yet, from the percentual changes it can be seen that some performance loss occurred at the elevated temperatures near the hydrogen inlet.

Fig. 7 shows the current density distribution at the cell temperature of $75^{\circ} \mathrm{C}$ and Table 3 the percentual difference to the reference. Almost all current is produced in the upper right area of the fuel cell and the left half of the cell is almost completely inactive. The water concentration should be highest at the hydrogen outlet, which lies at the pin area of $(12,1)$. At high temperature, water is vaporized and because of buoyancy, water concentration maximum shifts upward resulting in high current densities in these cell areas. On the other hand, the left side area is again dried because of dry inlet hydrogen leading to very high protonic resistance and preventing the formation of an uniform current distribution. The voltage in this case was approximately $0.35 \mathrm{~V}$.

Current density distributions were also measured at an average current density of $200 \mathrm{~mA} \mathrm{~cm}^{-2}$. However, this could be done only at cell temperatures of 45 and $60{ }^{\circ} \mathrm{C}$. At lower and higher temperatures the fuel cell could not operate above $0.2 \mathrm{~V}$. At ambient cell temperature the problem was the mass transport and at $75{ }^{\circ} \mathrm{C}$ the resistance of the fuel cell was limiting its performance.

Fig. 8 illustrates the current density distribution at the cell temperature of $45{ }^{\circ} \mathrm{C}$. The temperature gradient is no longer strong enough to form a homogenous current distribution. The best performing areas are again at the bottom of the fuel cell where oxygen concentration is the highest. The average voltage was $0.61 \mathrm{~V}$.

Fig. 9 shows the current density distribution at the cell temperature of $60{ }^{\circ} \mathrm{C}$. The distribution becomes smoother when the cell temperature is increased, which indicates than the oxygen concentration becomes more uniform along the gas channel. However, around the hydrogen inlet the cell performance is again not increased as much as in the other areas due to drying of the membrane or the electrodes (Table 4). The average cell voltage was $0.65 \mathrm{~V}$.

In addition to the distribution measurements, also polarization and resistance measurements were performed. Fig. 10 shows the polarization characteristics of the fuel cell at ambient, 45, 60, and $75{ }^{\circ} \mathrm{C}$ cell temperatures and Fig. 11 the behavior of resistance at same temperatures. In Fig. 10

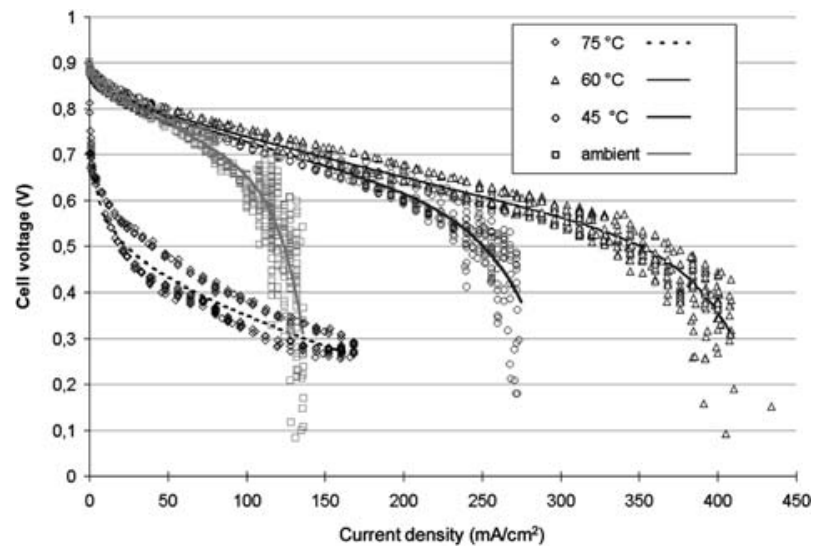

Fig. 10. Cell voltage as a function of current density at varied temperatures. Characters are measured data points and lines are average values calculated from Eq. (3).

also average polarization curves were calculated by using the semi-empirical equation introduced by Kim et al. [13]:

$E=E_{0}-b \log i-R i-m \mathrm{e}^{n i}$

where $E_{0}=E_{\mathrm{r}}+b \log i_{0}$ and $E_{\mathrm{r}}$ is the reversible potential, $i_{0}$ the exchange current density, $b$ the Tafel slope for oxygen reduction, $R$ the Ohmic resistance, and parameters $m$ and $n$ are experimental coefficients.

Some common features can be observed between the polarization and resistance curves, and the current density distribution plots. At cell temperatures from ambient to $60{ }^{\circ} \mathrm{C}$, the region below $50 \mathrm{~mA} \mathrm{~cm}{ }^{-2}$ is almost identical but at higher currents mass transport becomes limiting (Fig. 10). On the other hand, at the cell temperature of $75^{\circ} \mathrm{C}$ the limiting factor is not the mass transport but cell resistance (Fig. 11).

It is worth noticing that when the mass transport becomes limiting the cell voltage does not remain stable but tends to vary irregularly (Fig. 10). For example, at ambient cell temperature the voltage variation was between 0.1 and $0.6 \mathrm{~V}$ at a current density of $130 \mathrm{~mA} \mathrm{~cm}^{-2}$. It was observed

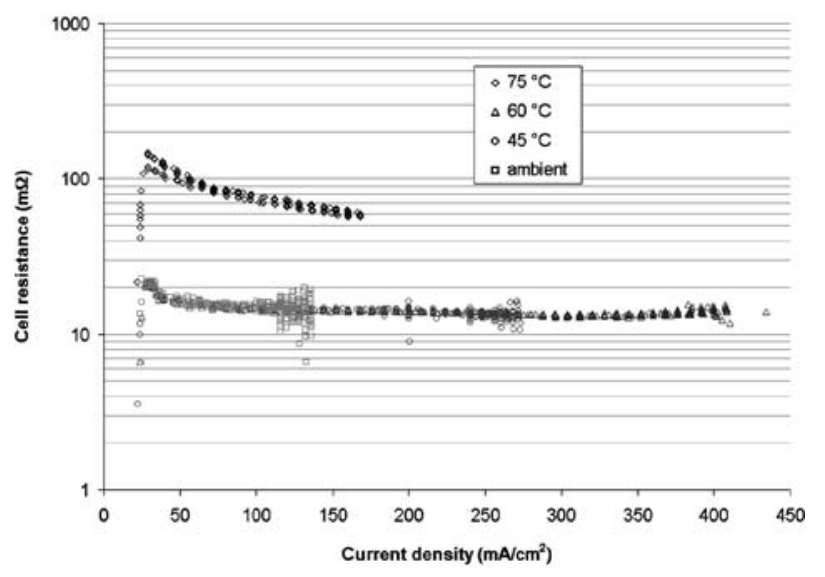

Fig. 11. Cell resistance as a function of current density at varied cell temperatures. 
during the measurements that these variations were often related to changes in the movement of air around the cell and in the laboratory room.

At transient current conditions the voltage varied also slightly but the variation was systematic. When the current was increased to a new level, the voltage initially dropped and then gradually stabilized. This was due to the fact that the airflow driven by the free convection followed the change in the load with a slight delay. The behavior was vice versa when the current was decreased.

It should be also noticed that the polarization measurement routine had a small influence on the polarization and resistance measurement results. At all temperature levels, the performance of the cell was slightly better on the way back from the maximum current, than during the first half of the scan. As it can be seen from Fig. 11, the cell resistance was lower during the latter half of the scan. From this it can be concluded that the humidification of the proton conductive phases was improved. This is most evident in the case where the cell temperature was $75^{\circ} \mathrm{C}$. The lower part of the curve is from the decreased current scan.

From Fig. 11 one can also see that the resistance was unstable in the cases where mass transport limitations were significant. This is due to the load unit, which cannot track fast changes when there is at the same time only small changes in current but large change in the voltage.

\section{The effect of non-segmented gas diffusion layer}

When the current distribution was calculated from the currents of the individual measurement pins, it was assumed that each pin collects current from an equal region, i.e. the division line between the regions lies exactly in the middle of the adjacent collectors. In our measurement system, the gas diffusion layer was not segmented. Therefore, it may be possible that the voltage profile inside the gas diffusion layer was distorted and division line was shifted from where it was assumed to be. Factors that may produce such distortions include, for example, unequal contacts of the measurement pins on the gas diffusion layer, local dry spots in the membrane or electrodes, or local barriers to airflow such as flooded gas diffusion layer or a water droplet in a gas channel.

In order to evaluate the error resulting from the shifted equipotential surfaces, a simple calculation was performed using the Femlab multiphysics package. The dc conductivity module of Femlab was used to solve the continuity equation:

$\nabla \cdot i=Q$

where $i$ is the current density and $Q$ is a current source. Combining Eq. (4) with the relation between the current density and electric field $i=\sigma E$ yields to the elliptic Poisson's equation:

$-\nabla \cdot(\sigma \nabla \phi)=Q$

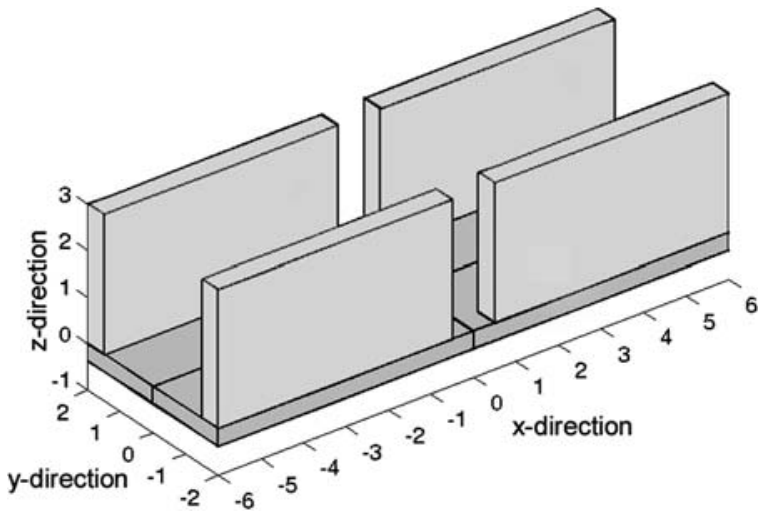

Fig. 12. The geometry used in the simulations. The current collectors are the vertical slabs and the gas diffusion layer segments are the horizontal plates.

where electric field is defined as $E=-\nabla \phi, \phi$ is the electric potential, and $\sigma$ is the material specific electric conductivity.

Because there are no current sources in the gas diffusion layer or in the current collectors, Eq. (5) is reduced to the form:

$-\nabla \cdot(\sigma \nabla \phi)=0$

The reaction areas, where current sources are located, are treated as Dirichlet boundary conditions, i.e. a current source is constant for a specific area.

A 3D calculation was performed in order to gain insight into the distribution of current between four neighboring pins. The model geometry is depicted in Fig. 12. The model geometry is roughly the same as in the segmented cathode plate. Each of the four slabs in the model is one-fourth of a current collector pin. The modeled contact area of each pin is $5.5 \mathrm{~mm} \times 0.5 \mathrm{~mm}$ with $1 \mathrm{~mm}$ gap between the pins and the width of the channel is $3 \mathrm{~mm}$. The gas diffusion layer is divided into four regions, each of them corresponding to the area from which the respective pin is assumed to collect current.

The current density of the electrode region under the segmented gas diffusion layer was modeled as a boundary condition. The current density was assumed to be $300 \mathrm{~mA} \mathrm{~cm}^{-2}$ under all other pins except the one in the region $x=[0 \mathrm{~mm}, 6 \mathrm{~mm}]$ and $y=[-2 \mathrm{~mm}, 0 \mathrm{~mm}]$, where it was assumed to be $150 \mathrm{~mA} \mathrm{~cm}^{-2}$. The values are in the typical current density range of a free-breathing PEMFC (see Fig. 10). The difference between the regions is rather extreme but it is possible under conditions where severe local drying or flooding takes place (see Fig. 7).

The electric resistance through plane of the gas diffusion layer is, according to the manufacturer, $10 \mathrm{~m} \Omega \mathrm{cm}^{2}$ and the thickness is $0.38 \mathrm{~mm}$. From these, the material conductance was estimated to be $3.8 \Omega^{-1} \mathrm{~cm}^{-1}$. The conductance of a current collector was estimated to be $100,000 \Omega^{-1} \mathrm{~cm}^{-1}$, which is a typical value for steel. The upper surfaces were assumed to be connected to a common ground resulting in the boundary condition $\phi=0 \mathrm{~V}$. Symmetric boundary conditions were used for the mirroring planes (the outer surfaces) of the pins and the gas diffusion layer regions. The 


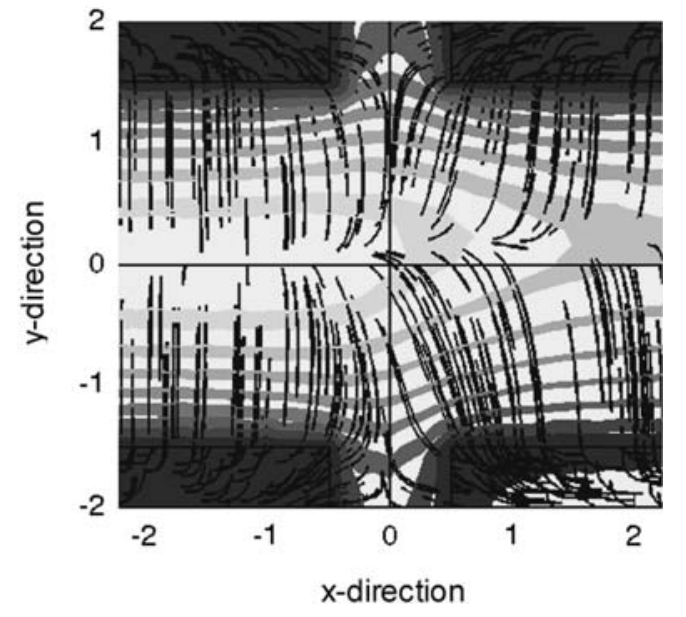

Fig. 13. Equipotential surfaces and current streamlines in the simulation case. The bottom-right section has the lowest current density.

model surfaces that correspond to real outer surfaces were given a zero current boundary condition.

The simulation result is shown in Fig. 13. Inspection of it reveals that the division line is, as expected, shifted slightly from the geometric centerline between the current collector pins. The pin, which was located to a lower current density region, is collecting current from a slightly larger area than the others. Accordingly, the areas from which the other pins are collecting current are reduced. Thus, if the areas are assumed to be equal, the measured current density distribution will appear slightly smoother than what it actually is. However, despite the quite extreme current density difference, the distortion appears to be tolerable and the results remain useful.

It must be remembered that the model included the assumption that there is an equally good contact between each pin and the diffusion layer. In reality, this assumption is of course not strictly true. However, even the rough quantification of the small contact resistances involved is very difficult and a computational analysis of their effect would therefore not be very well founded. In any case the calculation presented here leads to one important conclusion: current density distribution can be measured with a reasonable accuracy even if the gas diffusion layer is not segmented. However, the variation of contacts between the measurement pins and the gas diffusion layer have to be minimized.

\section{Conclusions}

Direct in situ measurement of a current density distribution from a free-breathing PEMFC is achieved with the measurement system reported here. The results showed clearly that the operating temperature had a significant influence on the fuel cell performance. Furthermore, at low cell temperatures the limiting factor was inadequate free convection and at high temperatures it was drying. It was shown, however, that under some operating conditions this type of fuel cell has fairly homogenous current distribution and therefore does not need any auxiliary pumps or fans to increase the airflow.

It was also shown that the gas diffusion layer does not have to be segmented because even large variations in spatial current distribution do not smoothen the current distribution profile significantly.

Although these measurements were performed with pure hydrogen, the reported results can be used also for a freebreathing direct methanol fuel cell because its cathode is similar.

In further studies, the measurement system will be used for investigations of the influence of ambient conditions and for the optimizations of the mass transport to a free-breathing PEMFC. Furthermore, the free-breathing cathode will be investigated through simulations in which the current distribution measurements are used for validation of the models.

\section{Acknowledgements}

The financial contribution of the National Technology Agent in Finland (Tekes) and the Nordic Energy Research (NEFP) is gratefully acknowledged. In addition, we wish to thank SGL Carbon for the gas diffusion layers. Computing resources were provided by CSC Scientific Computing Ltd.

\section{References}

[1] S.J.C. Cleghorn, C.R. Derouin, M.S. Wilson, S. Gottesfeld, J. Appl. Electrochem. 28 (1998) 663.

[2] J. Stumper, S.A. Campbell, D.P. Wilkinson, M.C. Johnson, M. Davis, Electrochim. Acta 43 (1998) 3773.

[3] Ch. Wieser, A. Helmbold, E. Gulzow, J. Appl. Electrochem. 30 (2000) 803.

[4] Ch. Wieser, A. Helmbold, W. Schnurnberger, Proceedings of the Electrochemical Society 98-27 (Proton Conducting Membrane Fuel Cells II), 1999, p. 457.

[5] A.R. Kucernak, N.P. Brandon, V. Vesovic, S. Atkins, D.J.L. Brett, N. Vasileiadis, Proceedings of the 1st European PEFC Conference, 2001, p. 297.

[6] T.E. Springer, T.A. Zawodzinski, M.S. Wilson, S. Gottesfeld, J. Electrochem. Soc. 143 (1996) 587.

[7] M. Watanabe, H. Uchida, M. Emori, J. Phys. Chem. B 102 (1998) 3129.

[8] J.A. Kolde, B. Bahar, M.S. Wilson, T.A. Zawodzinski, S. Gottesfeld, Proceedings of the Electrochemical Society, 95-23 (Proton Conducting Membrane Fuel Cells I), 1995, p. 193.

[9] T. Mennola, Design and experimental characterization of polymer electrolyte membrane fuel cells, Licentiate's Thesis, Helsinki University of Technology, 2000.

[10] M. Noponen, Experimental studies and simulations on proton exchange membrane fuel cell based energy storage systems, Master's Thesis, Helsinki University of Technology, 2000.

[11] M. Mikkola, Experimental studies on polymer electrolyte membrane fuel cell stacks, Master's Thesis, Helsinki University of Technology, 2001.

[12] F.N. Büchi, A. Marek, G. Scherer, J. Electrochem. Soc. 142 (1995) 1895.

[13] J. Kim, S.M. Lee, S. Srinivasan, C.E. Chamberlin, J. Electrochem. Soc. 142 (1995) 2670. 